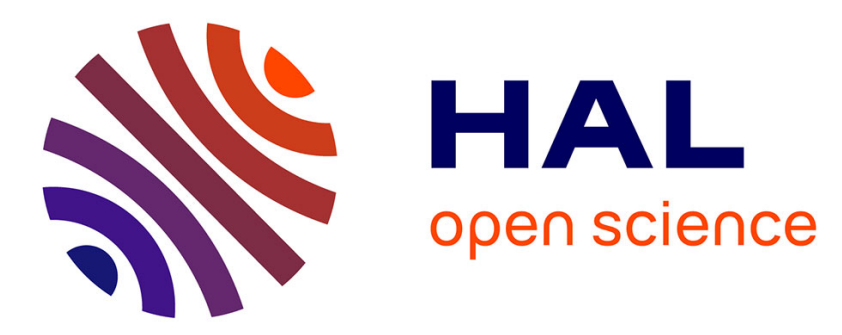

\title{
Analysis of the blank holder force effect on the preforming process using a simple discrete approach
}

Walid Najjar, Xavier Legrand, Philippe Dal Santo, Damien Soulat, Serge

Boude

\section{To cite this version:}

Walid Najjar, Xavier Legrand, Philippe Dal Santo, Damien Soulat, Serge Boude. Analysis of the blank holder force effect on the preforming process using a simple discrete approach. Key Engineering Materials, 2013, 554-557, pp.441-446. 10.4028/www.scientific.net/KEM.554-557.441 . hal-01207085

\section{HAL Id: hal-01207085 \\ https://hal.science/hal-01207085}

Submitted on 30 Sep 2015

HAL is a multi-disciplinary open access archive for the deposit and dissemination of scientific research documents, whether they are published or not. The documents may come from teaching and research institutions in France or abroad, or from public or private research centers.
L'archive ouverte pluridisciplinaire $\mathbf{H A L}$, est destinée au dépôt et à la diffusion de documents scientifiques de niveau recherche, publiés ou non, émanant des établissements d'enseignement et de recherche français ou étrangers, des laboratoires publics ou privés. 


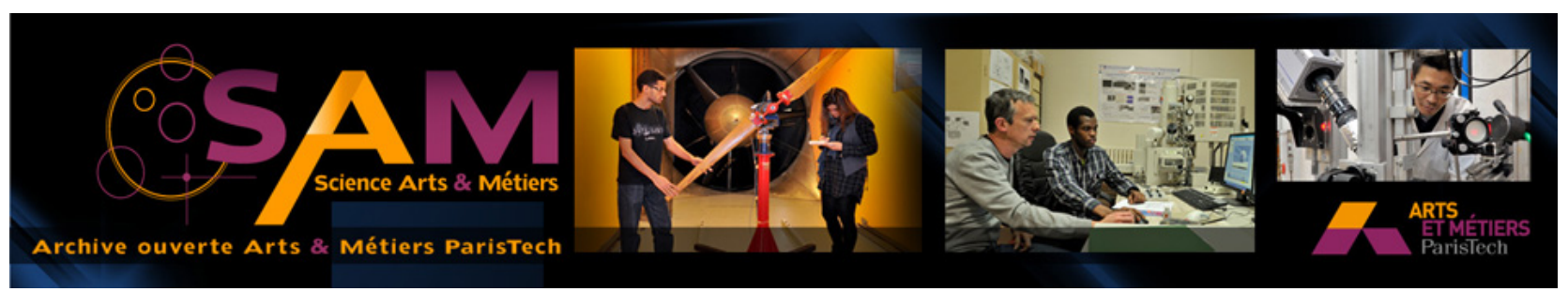

\section{Science Arts \& Métiers (SAM)}

is an open access repository that collects the work of Arts et Métiers ParisTech researchers and makes it freely available over the web where possible.

This is an author-deposited version published in: http://sam.ensam.eu

Handle ID: .http://hdl.handle.net/10985/10260

\section{To cite this version :}

Walid NAJJAR, Xavier LEGRAND, Philippe DAL SANTO, Damien SOULAT, Serge BOUDE Analysis of the blank holder force effect on the preforming process using a simple discrete approach - Key Engineering Materials - Vol. 554-557, p.441-446 - 2013 


\title{
Analysis of the blank holder force effect on the preforming process using a simple discrete approach
}

\author{
NAJJAR Walid, , , a , LEGRAND Xavier, b, DALSANTO Philippe ${ }^{2, c,}$ \\ SOULAT Damien ${ }^{1}$, BOUDE Serge ${ }^{2}$
}

\author{
${ }^{1}$ GEMTEX, Ecole Nationale des Arts et Industries Textiles, Lille University North of France \\ ${ }^{2}$ LAMPA, Arts et Métier ParisTech, centre Angers-France

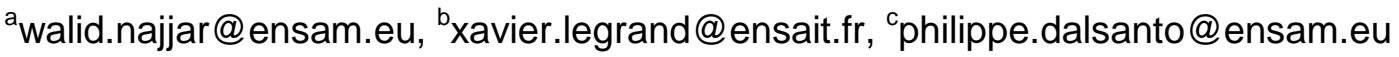

Keywords: Woven-fabric reinforcements, forming, finite element analysis.

\begin{abstract}
Simulation of the dry reinforcement preforming, first step of the Resin Transfer Moulding process, become necessary to determine the feasibility of the forming process, compute the fiber directions in the final composite component, and optimize process parameters during this step. Contrary to geometrical approaches, based on fishnet algorithms [1,2], finite element methods can take into account the actual physical parameters, the real boundary conditions and the mechanical behaviour of the textile reinforcement $[3,4]$. The fabric can be modelled either as continuum media with specific material behaviour [5, 6], or using discrete structural elements to describe the textile structure at the mesoscopic scale [7, 8]. A semidiscrete approach, which is a compromise between the above continuous and discrete approaches $[9,10]$, is also used for simulation. A discrete approach for the simulation of the preforming of dry woven reinforcement has been proposed and presented in a previous paper [11]. This model is based on a "unit cell" formulated with elastic isotropic shells coupled to axial connectors. The connectors, which replace bars or beams largely studied in other discrete approaches [12], reinforce the structure in the yarn directions and naturally capture the specific anisotropic behaviour of fabric. Shell elements are used to take into account the in-plane shear stiffness and to manage contact phenomena with the punch and die. The linear characteristic of the connectors [11], has been extended to a non linear behaviour in the present paper to better account for fabric undulation. Using this numerical model, we propose, in this work to study the effect of process parameters on the woven fabric deformation during the performing step. The emphasis will be placed on the analysis of the influence of the blank holder pressure on the shear angle distribution.
\end{abstract}

\section{Introduction}

Resin Transfer Molding (RTM) is one of the most used manufacturing processes for industrial composite materials [13]. The first step of the RTM is dry preforming of the fabric reinforcement sheet. During this forming step, significant local deformation may occur especially in-plane shear strains [14], which result in local variations of the textile reinforcement geometry. These variations strongly influence the permeability of the reinforcement and consequently affect the resin flow impregnation [15]. The local deformation of the reinforcement can also influence the mechanical properties of the final composite component. The simulation of this preforming step is used to have a response of the feasibility of the forming process and to verify the fibre directions in the final preformed fabric. 
Opposite to geometrical approaches, based on fishnet algorithms [1], finite element methods can take into account the mechanical behaviour of the textile reinforcement and the contact phenomena during forming simulation. Several methods for the finite element modelling of woven reinforcements have already been proposed. It is possible to consider the fabric as a continuum material obtained either by homogenization techniques (anisotropic behaviour) or with a no orthogonal constitutive modelling method [5], or with an anisotropic hypo-elastic or hyper-elastic continuous behaviour [17-18]. Discrete approaches [9, 10] are used to model the fabric structure at the mesoscopic scale. Semi discrete approaches, which are a compromise between the continuous and discrete approaches [3][8] have also been developed. In the present paper, a simplified method to simulate the preforming process is proposed, which aims to predict the shear angle distribution and to decrease calculation time. It is based on the coupling of a discrete approach (using non linear axial connectors) and a continuum shell formulation. Shell elements are used to take into account the in-plane shear stiffness, and to manage the contact phenomenon with the forming tools and eventually with an additional reinforcement ply. The connectors reinforce the structure in the yarn directions and naturally capture the specific axial behaviour of the fabric. This modelling approach is well adapted to describe the textile structure at the mesoscopic scale. In this paper an extension of this model which takes into account the undulation phenomenon is presented, the model has been then used to study the effect of blank holder force on the shear angles.

\section{Model description:}

In previous work, a discrete approach has been developed to simulate the stamping of woven fabric reinforcement and to predict yarn orientation of the deformed shape [11]. The structure of the numerical "unit cell" is shown in Fig. 1. It is a hybrid element built using a quadrilateral shell element (with 4 nodes) in which the four vertices are connected by axial connectors, along the edges of the element. The connectors control the tensile stiffness in the fabric, and naturally capture the anisotropy evolution of the textile media during deformation. The shell element, however, controls the in-plane shear stiffness and manages the contact phenomenon. This "hybrid element" describes a small portion of the fabric being considered (G1151 for instance), this portion is not necessarily the same size as the real unit cell of the woven fabric.
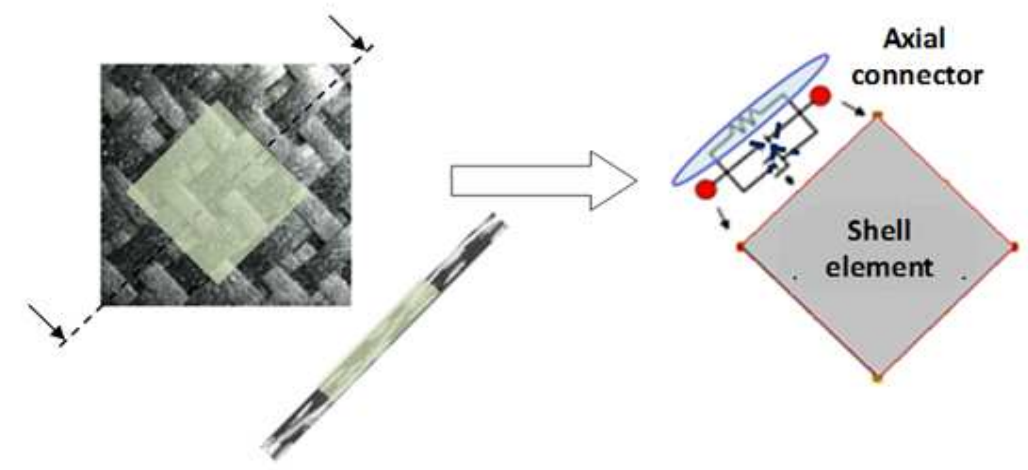

Figure 1: The unit cell model

The shell behaviour is elastic and it's identified using a bias test and an inverse optimisation method [11]. The connector behaviour can be either linear or nonlinear (polynomial), the 
identification of the connector stiffness is done using a uniaxial tensile test of a reinforcement specimen (Fig.2).
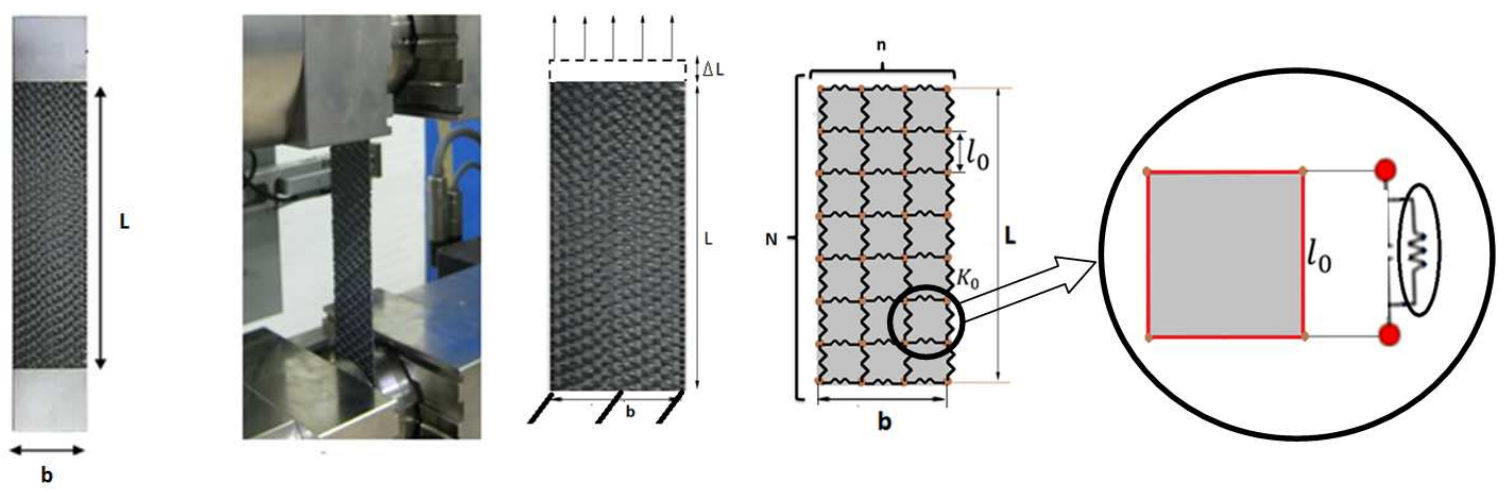

Figure 2 : Tensile test ( the real test and the equivalent modelled specimen using the shell elements and the connectors)

A summary of the model parameters is presented in the table below:

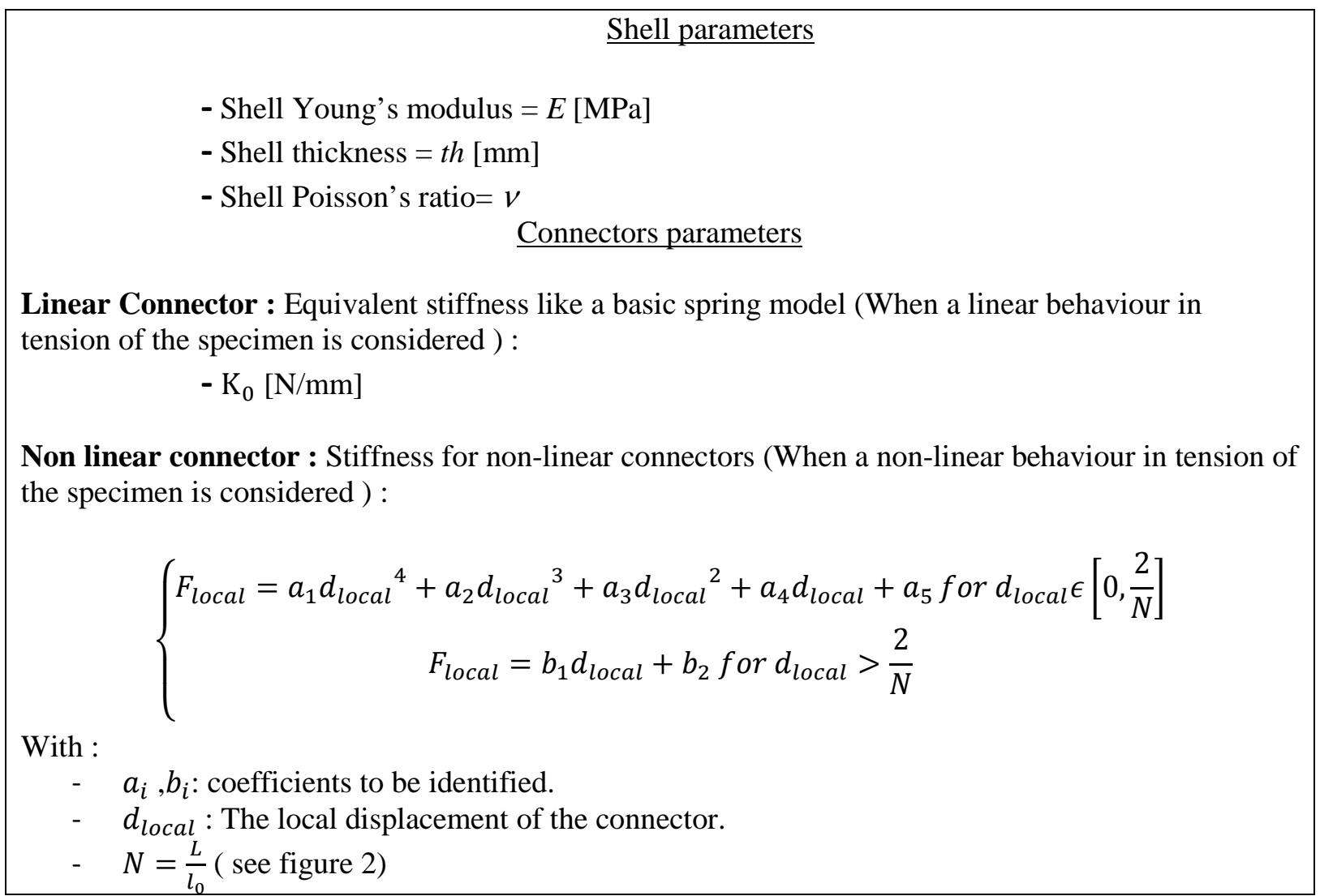

\section{Results}

The simulation results using linear and nonlinear connectors, and local measurements of the shear angles of the real preformed part, are presented in the following figures. 


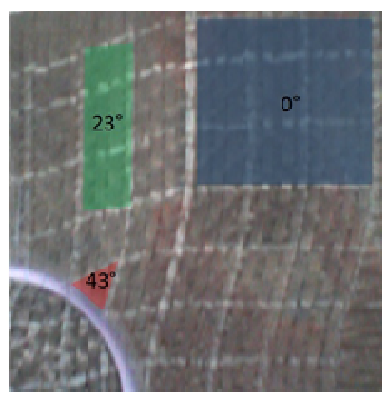

Figure 3: Experimental measurements

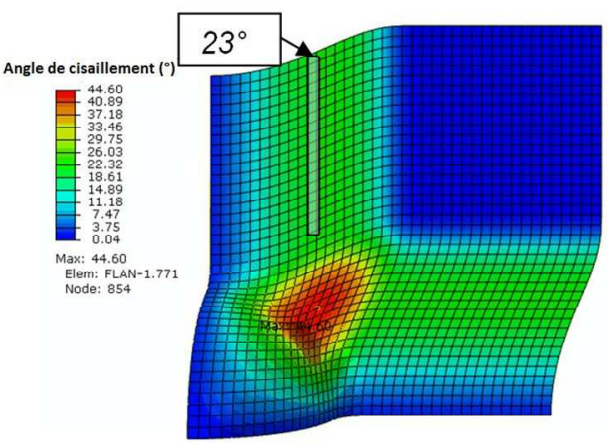

Figure 4: Shear angle computed with linear connectors

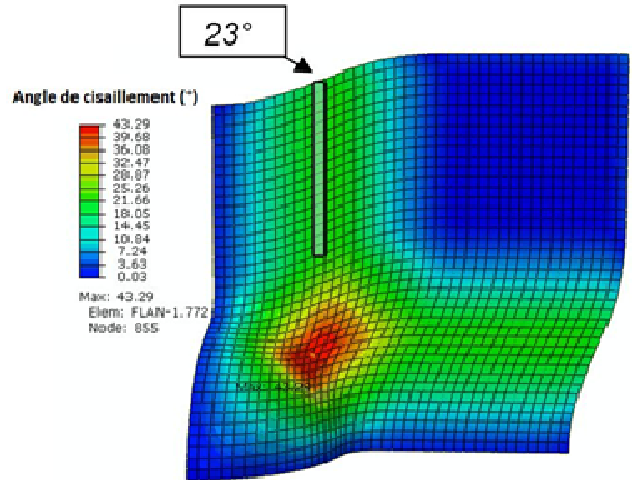

Figure 5 : Shear angle computed with non-linear connectors

Those figures show that the two models seem to correctly predict the shear angles in the areas of the flange, they also show that these models consider a coherent angle in the most critical area, however the nonlinear model is more realistic $\left(43_{-}^{+} 1^{\circ}\right.$ the real critical angle, $44.6^{\circ}$ the angle estimated by the linear model and $43.29^{\circ}$ angle calculated by the non-linear model). In addition, the nonlinear model seems to better predict the non-sheared zone. The linear model seems to slightly overestimate the surface of the area compared to the real surface. Indeed, the non-linear model predicts a smoother transition region, and a surface comparable to the non sheared real surface.

\section{Blank holder force analysis}

To analyze the effect of the blank holder force, shear angle profile along the dashed red line presented in the figure 6 are compared for different blank holder forces.

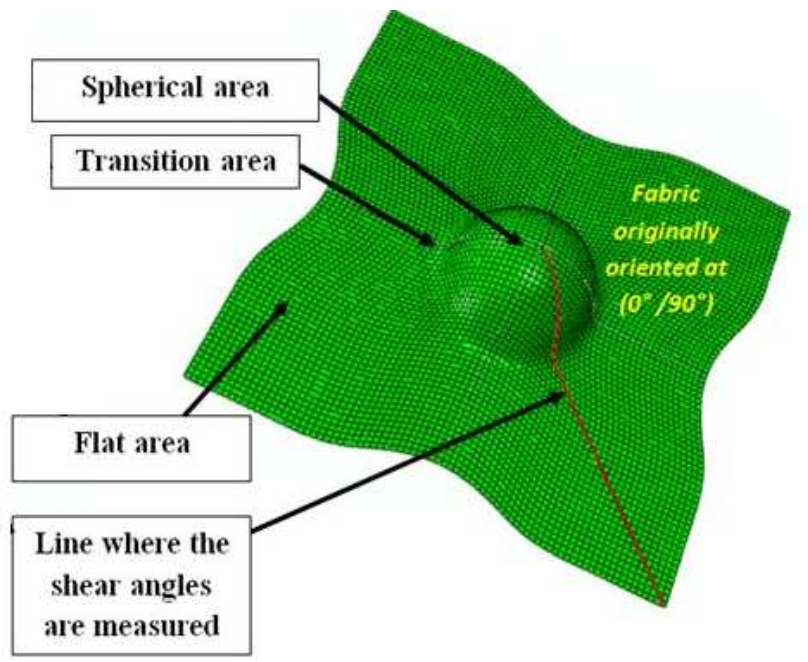

Figure 6: The unit cell model 
Three different values of blank holder force $(5 \mathrm{~N}, 50 \mathrm{~N}, 100 \mathrm{~N})$, have been used, the obtained angle profiles along the red line are presented in the figure 7 for the linear connectors and the figure 8 for the nonlinear connectors.

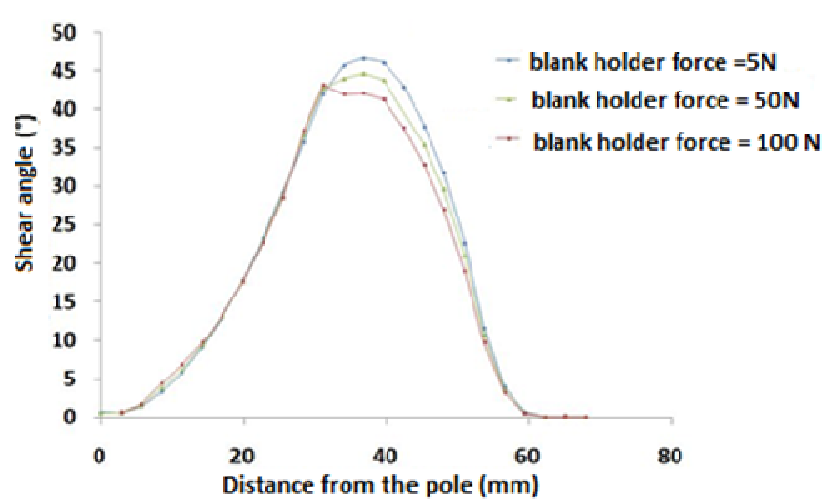

Figure 7: Shear angle profiles using linear connectors

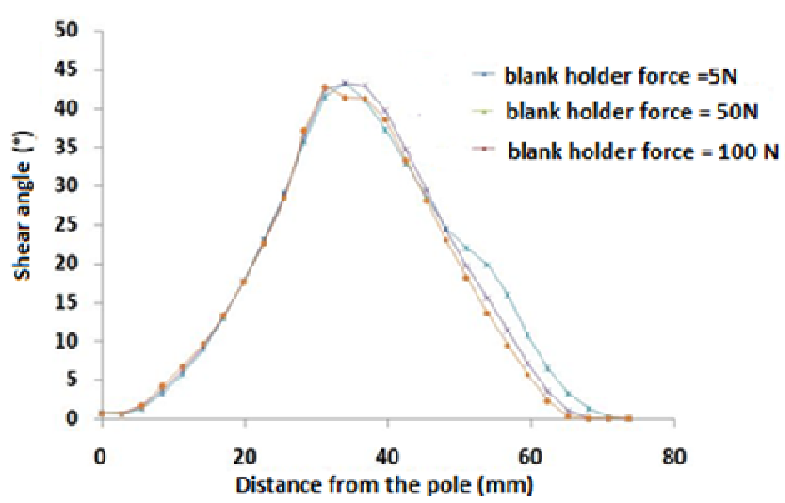

Figure 8: Shear angle profiles using non linear connectors

The curves of the figure 7 show that the blank holder force has an impact on the shear angles especially in the transition area. Indeed, in that most critical area (see figure 4 and figure $5^{\circ}$ ) the shear angle decreases when the blank holder force increases. This seems logical; indeed an increase in the blank holder force creates a high pressure perpendicular to the plane of reinforcement which makes the yarns working more in tension, limits the rotation of the connectors and then the shearing.

This result proves that the blank holder which is generally used to avoid the general membrane wrinkling is also very useful to avoid the wrinkling phenomenon specific to the woven reinforcement (local folding due to the shear angle locking), Indeed high blank holder load creates lower shear angles, and then less risk of local folding due to yarns locking.

Figure 8 presents the results using the non linear connector's behaviour. This result shows that the model is also sensitive to the blank holder force especially for the plane area underneath the blank holder, and we observe that the same tendency is observed also for this case, indeed the shear angle value increase when the blank holder forces decrease.

In conclusion, this study shows the efficiency and the physical aspect of this simple model which allows in addition to the shear angle prediction, to analyze the effect of the variation of boundary conditions and process parameters.

\section{Conclusion}

In this paper an extension of a discrete finite element woven fabric performing model presented in a previous work has been proposed. The result obtained using both original and the improved model was compared to experimental results, good agreement has been found for both cases. The effect of the blank holder force has been also, studied; an impact of the blank holder force on the shear angles has been revealed.

\section{Acknowledgement}

This work has been undertaken within the framework of the Défi composite project. The authors would like to thank Oséo for its financial support, the project leader Airbus-France and other partners (EADS IW and LoireTech) for provided facilities. 


\section{References}

[1] F.Van Der Ween, Algorithms for draping fabrics on doubly curved surfaces. Int. J. of Num. Meth. in Eng. 31, 1414-1426 (1991)

[2] A.C. Long, C.D. Rudd, simulation of reinforcement deformation during the production of preform for liquid moulding processes, I. Mech. E.J. Eng. Manuf. 208,269-278 (1994) .

[3] A. Cherouat, J.L. Billoet, Mechanical and numerical modelling of composite manufacturing processes deep-drawing and laying-up of thin pre-impregnated woven fabrics. J. Mater. Process. Technol. 118, 460-471, (2001)

[4] W.R. Yu, F. Pourboghrat, K. Chung, M. Zamploni, T.J. Kang, Compos. Part A 33 (2002) 10951105.

[5] P.Xue, X.Peng X, J.Cao. A non-orthogonal constitutive model for characterizing woven composites. Compos Part A 34:183-193(2003).

[6]. A. Charmetant, E. Vidal-Sallé, P. Boisse. Hyperelastic modelling for mesoscopic analyses of composite reinforcements. Composites Science and Technology, 71,1623-1631, (2011).

[7]B.Ben Boubaker,B.Haussy,J.F Ganghoffer discrete models of woven structures. Macroscopic approach. Compos Part B 38:498-505,(2007).

[8] A.A.Skordos, C.Monroy Aceves, M.P.F.Sutcliffe. A simplified rate dependent model of forming and wrinkling of pre-impregnated woven composites. Composite Part A, 38, 1318-1330, (2007)

[9] N. Hamila, P. Boisse, F. Sabourin, M. Brunet. A semi-discrete shell finite element for textile composite reinforcement forming simulation. International Journal for Numerical Methods in Engineering, 79(12), 1443-1466,(2009)

[10] S.Allaoui,P.Boisse,S.Chatel,N.Hamila,G.Hivet,D.Soulat,E.Vidal-Salle, Experimental and numerical analyses of textile reinforcement forming of a tetrahedral shape, Composites Part A, 42:612-622,(2011)

[11] W. Najjar, X.Legrand, C.Pupin, P.DalSanto, S.Boude, A simple discrete method for the simulation of the preforming of woven fabric reinforcement. Key Engineering Materials, 504-506, 213-218, (2012)

[12]D.Jauffrés,J.A.Sherwood, Discrete mesoscopic modeling for the simulation of woven-fabric reinforcement forming. International Journal of Material forming, 3(Suppl 2): 1205-1216, (2010)

[13] Rudd CD and Long AC (1997). Liquid molding technologies. Woodhead Publishing Limited, 1997.

[14] Badel P, Vidal-Salle E, Boisse P (2007). Computational determination of in-plane shear mechanical behavior of textile composite reinforcements. Computational Materials Science. 40:439448

[15].Arbter et al (2011). Experimental determination of the permeability of textiles: A benchmark exercise. Composites Part A,42: 1157-1168

[16].Long AC and Rudd CD (1994). Simulation of reinforcement deformation during the production of preform for liquid moulding processes, I. Mech. E.J. Eng. Manuf. 208,269-278.

[17] A.Yamina, E. Vidal-Sallé, B. Hagège, F. Sidoroff, P. Boisse. A hyperelastic approach for composite reinforcement large deformation analysis. Journal of Composite Materials, 44(1), 2010, 522.

[18]M. A. Khan, T. Mabrouki, E. Vidal-Sallé, P. Boisse. numerical and experimental analyses of woven composite reinforcement forming using a hypoelastic behaviour.application to the double dome benchmark .Reinforcement Forming using a Hypoelastic Behaviour. J Mat Processing Tech, 210,2010, 378-388. 